\title{
A Comparative Study on Antioxidant Activity and Inhibitory Potential against Key Enzymes Related to Type 2 Diabetes of Four Typical Teas
}

\author{
Dedong Kong ${ }^{1}$, Jing $\mathrm{Wu}^{2}$, Shili Sun ${ }^{3}$, Yuefei Wang ${ }^{2}$, Ping $\mathrm{Xu}^{1,2, *}$ \\ ${ }^{1}$ Agricultural Experiment Station of Zhejiang University, Hangzhou, China \\ ${ }^{2}$ Department of Tea Science, Zhejiang University, Hangzhou, China \\ ${ }^{3}$ Drinkable Plants Institute (Tea Research Center ), Guangdong Provincial Key Laboratory of Tea Plant Resources Innovation and \\ Utilization, Guangzhou, China \\ *Corresponding author: zdxp@zju.edu.cn
}

Received August 30, 2014; Revised September 12, 2014; Accepted September 16, 2014

\begin{abstract}
Tea (Camellia sinensis L.) is categorized into four types depending on the degree of fermentation, which in turn affects the physicochemical properties of tea. In this work, aqueous extracts of four typical teas, named green tea, oolong tea, black tea and puerh tea, were obtained, and their chemical compositions and bioactivities including antioxidant activity and inhibition on $\alpha$-amylase and $\alpha$-glycosidase were compared. It was found oolong and green tea not only possessed stronger antioxidant ability in assays of DPPH, ABTS and FRAP, but also had more power on inhibition on $\alpha$-amylase and $\alpha$-glycosidase. Pearson correlation analysis showed tea polyphenols and catechins had significant positive correlations on $\alpha$-amylase inhibition. However, caffeine was observed to have a significant negative effect on $\alpha$-glycosidase inhibition. These results indicated teas with no or slight fermentation (decaffeinated was better), were suitable for diabetes.
\end{abstract}

Keywords: tea, fermentation, antioxidant activity, hyperglycemia, decaffeinated

Cite This Article: Dedong Kong, Jing Wu, Shili Sun, Yuefei Wang, and Ping Xu, "A Comparative Study on Antioxidant Activity and Inhibitory Potential against Key Enzymes Related to Type 2 Diabetes of Four Typical Teas.” Journal of Food and Nutrition Research, vol. 2, no. 9 (2014): 652-658. doi: 10.12691/jfnr-2-9-20.

\section{Introduction}

Tea (Camellia sinensis L.) is the 2nd most consumed beverage in the world and can be categorized into four types, depending on the degree of fermentation during manufacturing, namely green (unfermented) tea, oolong (semi-fermented) tea, black (fermented) tea and puerh (post-fermented) tea (Lin and Lin-Shiau, 2006). Despite all teas are derived from green tea leaves, they can be divided into four typical categories mainly by degree of fermentation. For example, no fermentation is involved in processing of green tea, and semi-fermentation is employed in processing of oolong tea, total fermentation and post-fermentation (named pile fermentation) are used in manufacture of black and puerh tea, respectively. Complex alterations occur in chemicals during various degrees of fermentation not only leading to distinctive flavor of teas, but also resulting in an obscure understanding of chemical compositions in teas except green tea (unfermented tea). Recently, oolong tea and puerh tea has attracted increasing attention not only for their special flavors, but also for their unique health promoting effects (Wang et al., 2012; Xu et al., 2014; Huang et al., 2013). The health benefits of tea are associated with its constituents, such as tea polysaccharide, tea polyphenols (or catechin), caffeine, protein, amino acids.

Tea has been used as a popular folk prescription for curing diabetes in Southeast Asia, especially in Japan and China (Wang, 1988). Previously, antioxidant activity and inhibitory potential against $\alpha$-glycosidase and $\alpha$-amylase of teas, including green tea, oolong tea, black tea, and puerh tea, has been investigated, which was suggested to contribute to their hypoglycemic effect. (Wang et al., 2001; Zhou et al., 2007; Wang et al., 2008). However, till now, the different activity among teas is still obscure, and no consensus has been reached on which constituent is mainly responsible for the hypoglycemic effect of tea. That is mainly because constituents vary from each other in different kinds of teas and few comparative studies have been carried out.

Therefore, the objectives of this study were to obtain aqueous extracts of green tea, black tea, oolong tea, and puerh tea, and to compare their chemicals and bioactivities, including antioxidant activity and inhibitory potential against $\alpha$-amylase and $\alpha$-glycosidase, and to analyze correlation of bioactivities and chemicals by Pearson correlation analysis.

\section{Materials and Methods}




\subsection{Materials}

Green tea, Black tea, Oolong tea and Puerh tea were obtained from Hangzhou Efuton Tea Co. (Hangzhou, China). Folin-Ciocalteu's phenol reagent, gallic acid, 2,2'azinobis (3-ethylbenzothiazoline-6-sulfonic acid) diammonium salt (ABTS), 2,2-diphenyl-1-picryl-hydrazyl (DPPH), 2,4,6-tripyridyl-s-triazine (TPTZ), baker's yeast $\alpha$-glycosidase (EC 3.2.1.20), porcine pancreatic $\alpha$-amylase (EC 3.2.1.1), $p$-nitrophenyl- $\alpha$-D-glucopyranoside ( $p N P G$ ) and all the catechin standards were purchased from Sigma Chemical Co. (Missouri, USA). Methanol and acetonitrile of HPLC grade were purchased from Tianjin Shield Co. (Tianjin, China). All other chemicals were analytical grade and purchased from Sinopharm Chemical Reagent Co. (Shanghai, China).

\subsection{Preparation of Aqueous Extracts of Teas}

Each tea sample (5 g) was refluxed with $50 \mathrm{vol}(\mathrm{v} / \mathrm{w})$ of distilled water at $100^{\circ} \mathrm{C}$ for $10 \mathrm{~min}$, and the extraction was repeated twice. The extracts were filtered through filter paper, concentrated to $10 \%$ with a vacuum evaporator at $45^{\circ} \mathrm{C}$, and dried with a freeze drier. Then the freeze-dried aqueous extracts were obtained.

\subsection{Composition Analysis}

Tea polyphenolic content was determined according to the Folin-Ciocalteu method modified by Ranilla et al. (2010). Tea polysaccharides content was measured by the anthrone-sulfuric acid method (Morris, 1948) using glucose as standard. Protein was analyzed by the method of Bradford (1976) using bovine serum albumin as the standard. Amino acid content was determined by the ninhydrin assay method (Liang et al., 2005) using theanine as standard. Caffeine and tea catechins, including C, (+)-catechin; CG, (+)-catechin gallate; EC, (-)epicatechin; ECG, (-)-epicatechin gallate; EGC, (-)epigallocatechin; EGCG, (-)-epigallocatechin gallate; GC, (+)-gallocatechin; GCG, (+)-gallocatechin gallate, were determinated according to the HPLC method described by Liang et al. (2007), using a Shimadzu SCL-10A HPLC system (Shimadzu Corporation, Tokyo, Japan).

\subsection{DPPH Scavenging Activity}

The DPPH free radical scavenging activities of the extracts were determined by the method of Mohsen and Ammar (2009), with a slight modification. One ml of the tested samples at various concentrations (12-60 $\mu \mathrm{g} / \mathrm{ml})$ was added to $3 \mathrm{ml}$ of ethanolic DPPH solutions $(0.1 \mathrm{mM})$. Discolorations were measured at $517 \mathrm{~nm}$ after incubation for $30 \mathrm{~min}$ at $30^{\circ} \mathrm{C}$ in the dark. The $\mathrm{DPPH}$ scavenging effect was calculated as follows:

DPPH scavenging effect $(\%)=\left(1-\mathrm{A}_{\text {samp }} / \mathrm{A}_{\text {cont }}\right) \times 100$

where $\mathrm{A}_{\text {samp }}$ and $\mathrm{A}_{\text {cont }}$ were defined as absorbance of the sample and the control, respectively.

\subsection{ABTS Cation Radical Scavenging Capacity}

ABTS assay was carried out according to the method of Cai et al. (2004). The ABTS cation radical solution was prepared by mixing $7 \mathrm{mM}$ ABTS and $2.45 \mathrm{mM}$ potassium persulphate and incubating in the dark at room temperature for $12 \mathrm{~h}$. The ABTS cation radical solution was then diluted with water to obtain an absorbance of $0.70 \pm 0.02$ at $734 \mathrm{~nm}$. ABTS cation radical solution (3 ml) was added to $0.1 \mathrm{ml}$ of the test sample with various concentrations (12 - $60 \mu \mathrm{g} / \mathrm{ml}$ ) and mixed vigorously. The absorbance was measured at $734 \mathrm{~nm}$ after standing for 6 min. The ABTS scavenging effect was calculated as follows:

ABTS scavenging effect $(\%)=\left(1-\mathrm{A}_{\text {samp }} / \mathrm{A}_{\text {cont }}\right) \times 100$

where $\mathrm{A}_{\text {samp }}$ and $\mathrm{A}_{\text {cont }}$ were defined as absorbance of the sample and the control, respectively.

\subsection{Reducing Activity}

The ferric-reducing antioxidant power (FRAP) assay was performed according to a modified method of Benzie and Strain (1999). Briefly, the working FRAP reagent was prepared by mixing $10 \mathrm{vol}$ of $300 \mathrm{mM}$ acetate buffer (pH 3.6) with 1 vol TPTZ $(10 \mathrm{mM})$ in $\mathrm{HCl}(40 \mathrm{mM})$ and with 1 vol of $\mathrm{FeCl}_{3}(20 \mathrm{mM})$. Freshly prepared FRAP reagent was warmed at $37^{\circ} \mathrm{C}$, and a reagent blank reading was taken at $593 \mathrm{~nm}$. Subsequently, $0.6 \mathrm{ml}$ of sample was added to the FRAP reagent $(4.5 \mathrm{ml})$. A second reading at $593 \mathrm{~nm}$ was performed after $8 \mathrm{~min}$. The initial blank reading with the FRAP reagent alone was subtracted from the final reading of the FRAP reagent with the sample to determine the FRAP value of the sample. A standard curve was prepared using different concentrations of $\mathrm{FeSO}_{4} \cdot 7 \mathrm{H}_{2} \mathrm{O}$. The reducing ability of the extracts was expressed as the equivalent to that of $1 \mu \mathrm{M} \mathrm{FeSO}_{4} \cdot 7 \mathrm{H}_{2} \mathrm{O}$.

\section{7. $\alpha$-Amylase Inhibition Activity}

The $\alpha$-amylase inhibitory activity of the extracts was determined according to a modification of the method of Ranilla et al. (2010). A total of $250 \mu \mathrm{l}$ of sample and 125 $\mu \mathrm{l}$ of $0.02 \mathrm{M}$ sodium phosphate buffer ( $\mathrm{pH} 6.9$ with $6 \mathrm{mM}$ $\mathrm{NaCl})$ containing $\alpha$-amylase solution $(0.5 \mathrm{mg} / \mathrm{ml})$ were incubated at $25^{\circ} \mathrm{C}$ for $10 \mathrm{~min}$. After preincubation, $250 \mu \mathrm{l}$ of $1 \%$ starch solution in $0.02 \mathrm{M}$ sodium phosphate buffer (pH 6.9 with $6 \mathrm{mM} \mathrm{NaCl}$ ) was added to each tube at timed intervals. The reaction mixtures were then incubated at $25^{\circ} \mathrm{C}$ for $10 \mathrm{~min}$. The reaction was stopped with $0.5 \mathrm{ml}$ of dinitrosalicylic acid color reagent. The test tubes were then incubated in a boiling water bath for $5 \mathrm{~min}$ and cooled to room temperature. The reaction mixture was then diluted after adding $5 \mathrm{ml}$ of distilled water, and absorbance was measured at $540 \mathrm{~nm}$. The $\alpha$-amylase inhibitory activity was calculated as follows:

$$
\text { Inhibition }(\%)=\left(1-\mathrm{DA}_{\text {samp }} / \mathrm{DA}_{\text {cont }}\right) \times 100
$$

where $\mathrm{A}_{\text {samp }}$ and $\mathrm{A}_{\text {cont }}$ were defined as absorbance of the sample and the control, respectively.

\section{8. $\alpha$-Glycosidase Inhibitory Activity}

The $\alpha$-glycosidase inhibitory activities of the extracts were determined according to the method described by Apostolidis and Lee (2010) with a slight modification. A mixture of $50 \mu \mathrm{l}$ of sample and $100 \mu \mathrm{l}$ of $0.1 \mathrm{M}$ phosphate buffer ( $\mathrm{pH}$ 6.9) containing $\alpha$-glycosidase solution $(1 \mathrm{U} / \mathrm{ml})$ 
was incubated in 96 well plates at $25^{\circ} \mathrm{C}$ for $10 \mathrm{~min}$. After preincubation, $50 \mu \mathrm{l}$ of $5 \mathrm{mM} p \mathrm{NPG}$ solution in $0.1 \mathrm{M}$ phosphate buffer ( $\mathrm{pH}$ 6.9) was added to each well at timed intervals. The reaction mixtures were incubated at $25^{\circ} \mathrm{C}$ for $5 \mathrm{~min}$. Before and after incubation, absorbance was recorded at $405 \mathrm{~nm}$ by microplate reader (SpectraMax M5, Molecular Devices, California, USA). The $\alpha$-glycosidase inhibitory activity was expressed as inhibition percent and was calculated as follows:

$$
\text { Inhibition }(\%)=\left(1-\mathrm{DA}_{\text {samp }} / \mathrm{DA}_{\text {cont }}\right) \times 100
$$

where $\mathrm{A}_{\text {samp }}$ and $\mathrm{A}_{\text {cont }}$ were defined as absorbance of the sample and the control, respectively.

\subsection{Statistical Analysis}

All the experiments were carried out in triplicate. The results were expressed as means $\pm \mathrm{SD}$ and evaluated by analysis of variance (ANOVA) followed by Tukey's studentized range test carried out on the SAS system for windows V9, and $\mathrm{p}<0.05$ was regarded as statistically significant.

\section{Results}

\subsection{Chemical Compositions}

The contents of chemicals, including tea polyphenols, polysaccharides, protein, amino acid, caffeine, and catechins, in tea extracts are presented in Table 1 . It can be seen that oolong tea extract had the highest contents of tea polyphenols (31.56\%), tea polysaccharides (30.19\%), and total catechins (23.31\%). And black tea extract had the highest content of amino acid (12.62\%). The highest contents of protein and caffeine were found in the extract of puerh tea, which were $8.9 \%$ and $9.96 \%$, respectively.

Table 1. Chemical analysis of the tea extracts (g/g of dry weight of extract)

\begin{tabular}{|c|c|c|c|c|}
\hline \multirow{2}{*}{ Contents } & \multicolumn{4}{|c|}{ Extracts } \\
\hline & Oolong Tea & Black Tea & Puerh Tea & Green Tea \\
\hline Tea Polyphenol & $31.56 \pm 5.34$ & $11.69 \pm 0.84$ & $17.72 \pm 0.76$ & $25.92 \pm 2.54$ \\
\hline Tea Polysaccharides & $30.19 \pm 4.13$ & $18.48 \pm 1.21$ & $20.25 \pm 1.07$ & $20.94 \pm 1.13$ \\
\hline Protein & $6.26 \pm 0.51$ & $5.85 \pm 0.56$ & $8.90 \pm 0.48$ & $5.82 \pm 0.17$ \\
\hline Amino Acid & $10.78 \pm 0.32$ & $12.62 \pm 0.16$ & $10.11 \pm 0.14$ & $11.90 \pm 0.38$ \\
\hline Caffeine & $5.26 \pm 0.57$ & $8.09 \pm 0.21$ & $9.96 \pm 1.03$ & $7.36 \pm 0.29$ \\
\hline Total Catechins & $23.31 \pm 3.45$ & $9.02 \pm 0.58$ & $10.20 \pm 0.73$ & $21.05 \pm 2.64$ \\
\hline GC & $6.85 \pm 0.14$ & $6.24 \pm 0.22$ & $9.54 \pm 0.54$ & $6.62 \pm 0.76$ \\
\hline EGC & $5.05 \pm 0.82$ & $1.47 \pm 0.08$ & $0.37 \pm 0.09$ & $6.29 \pm 1.04$ \\
\hline $\mathrm{C}$ & $0.73 \pm 0.08$ & $0.32 \pm 0.07$ & $0.05 \pm 0.01$ & $0.89 \pm 0.02$ \\
\hline EC & $3.23 \pm 0.89$ & $0.56 \pm 0.17$ & $0.05 \pm 0.003$ & $3.42 \pm 0.37$ \\
\hline EGCG & $3.26 \pm 0.62$ & $0.08 \pm 0.01$ & $0.02 \pm 0.001$ & $2.53 \pm 0.33$ \\
\hline GCG & $2.02 \pm 0.54$ & $0.04 \pm 0.004$ & $0.01 \pm 0.001$ & $0.43 \pm 0.05$ \\
\hline ECG & $1.74 \pm 0.20$ & $0.11 \pm 0.01$ & $<0.01$ & $0.72 \pm 0.06$ \\
\hline CG & $0.43 \pm 0.16$ & $0.20 \pm 0.02$ & $0.16 \pm 0.08$ & $0.15 \pm 0.01$ \\
\hline
\end{tabular}

GC, (+)-gallocatechin; EGC, (-)-epigallocatechin; C, (+)-catechin; EC, (-)-epicatechin; EGCG, (-)-epigallocatechin gallate; GCG, (+)-gallocatechin gallate; ECG, (-)-epicatechin gallate; $\mathrm{CG},(+)$-catechin gallate.

Table 2. Effective concentrations of the tea extracts on antioxidant activity and inhibition on key enzymes related to type 2 diabetes

\begin{tabular}{|c|c|c|c|c|c|}
\hline & ABTS $(\mathrm{EC} 30, \mu \mathrm{g} / \mathrm{ml})$ & DPPH (EC30, $\mu \mathrm{g} / \mathrm{ml})$ & FRAP $(30 \mu \mathrm{g} / \mathrm{ml})$ & $\alpha$-amylase $(\mathrm{EC} 50, \mu \mathrm{g} / \mathrm{ml})$ & Glycosidase (EC30, $\mu \mathrm{g} / \mathrm{ml})$ \\
\hline Oolong Tea & 17.46 & 36.56 & 96.13 & 7491.16 & 21.44 \\
\hline Black Tea & 33.47 & 52.07 & 74.00 & 9751.68 & 31.72 \\
\hline Puerh Tea & 51.53 & 47.16 & 82.50 & 9115.22 & 48.49 \\
\hline Green Tea & 22.90 & 24.67 & 49.75 & 8405.61 & 14.58 \\
\hline
\end{tabular}

\subsection{Antioxidant Properties}

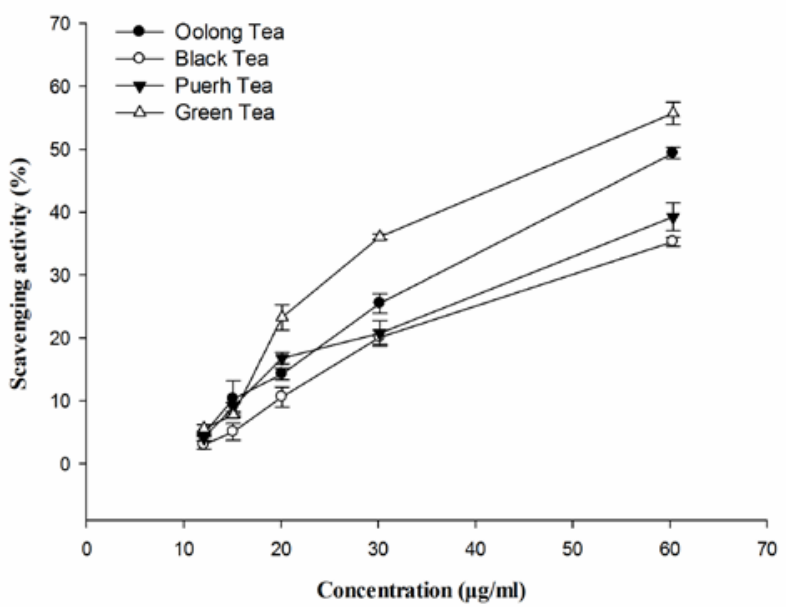

Figure 1. DPPH scavenging activity of the tea extracts

The scavenging ability of tea extracts on DPPH free radical is shown in Figure 1 . In this assay, the concentration-dependent profile of scavenging power was obvious for all the extracts. By comparing the $\mathrm{EC}_{30}$ values
(Table 2), the scavenging effect of the extracts increased in the order of green tea $>$ oolong tea $>$ puerh tea $>$ black tea.

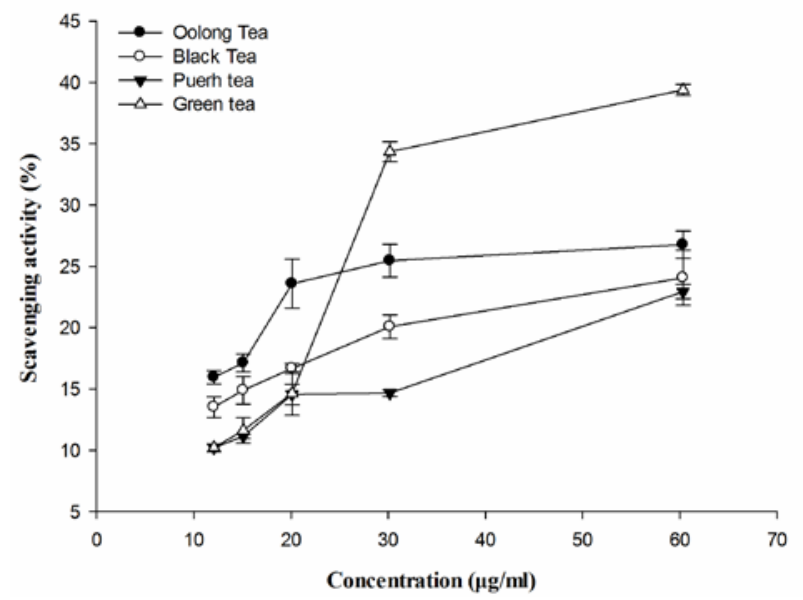

Figure 2. ABTS scavenging activity of the tea extracts

The ABTS cation radical scavenging activities of the extracts are depicted in Figure 2 and the $\mathrm{EC}_{30}$ values of the extracts are presented in Table 2. Obviously, the scavenging effects of extracts on ABTS cation radicals 
were in the order of oolong tea $>$ green tea $>$ black tea $>$ puerh tea with the $\mathrm{EC}_{30}$ of $17.46 \mu \mathrm{g} / \mathrm{ml}, 22.90 \mu \mathrm{g} / \mathrm{ml}$, $33.47 \mu \mathrm{g} / \mathrm{ml}, 51.53 \mu \mathrm{g} / \mathrm{ml}$, respectively.

The results of FRAP assay are shown in Figure 3. All of the extracts exhibited reducing ability on TPTZ-Fe (III) complex to TPTZ-Fe (II) complex in a concentrationdependent manner. The reducing capacity of green tea increasing dramatically at the range of high concentrations, but by comparing the FRAP values of the extracts at the concentration of $30 \mu \mathrm{g} / \mathrm{ml}$ (Table 2). It can be seen the ferric-reducing power of the extracts increased in the order: oolong tea $>$ puerh tea $>$ black tea $>$ green tea.

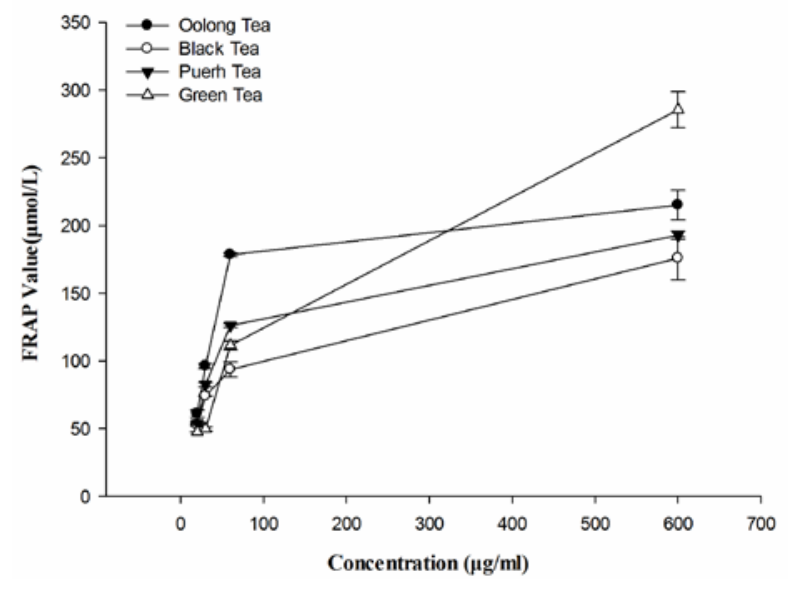

Figure 3. Ferric-reducing antioxidant power (FRAP) of the tea extracts

\subsection{Inhibitory Potential against $\alpha$-amylase}

The $\alpha$-amylase inhibitory effects of tea extracts are shown in Figure 4. All the extracts presented a doseresponse relation between the concentration and inhibition.
It can be concluded that oolong tea exhibited the strongest inhibitory effect on $\alpha$-amylase followed by green tea and black tea. Puerh tea showed the weakest inhibition on $\alpha$ amylase. The values of $\mathrm{EC}_{50}$ were $7491 \mu \mathrm{g} / \mathrm{ml}, 8405$ $\mu \mathrm{g} / \mathrm{ml}, 9115 \mu \mathrm{g} / \mathrm{ml}, 9751 \mu \mathrm{g} / \mathrm{ml}$ for oolong tea, green tea, black tea and puerh tea, respectively (Table 2).

\subsection{Inhibitory Activity on $\alpha$-glycosidase}

The inhibitory effects of the extracts on $\alpha$-glycosidase are shown in Figure 5 and their $\mathrm{EC}_{30}$ values are presented in Table 2. It can be observed that all the extracts showed a concentration-dependent inhibition on $\alpha$-glycosidase. Unlike the results from $\alpha$-amylase inhibition assay, green tea presented the strongest inhibitory effect on $\alpha$ glycosidase. Obviously, the inhibition on $\alpha$-glycosidase of the extracts increased in the order: green tea $>$ oolong tea $>$ black tea $>$ puerh tea.

\subsection{Relationship between the Contents of Constituents in the Extracts and their Bioactivities}

In order to figure out which constituent of tea is mainly responsible for the bioactivities, the relationship between the main constituents in the extracts and their bioactivity was analyzed by Pearson's correlation coefficient (Table 3). As shown, siginificant positive correlation (Pearson's correlation coefficient was 0.974, $p<0.05$ ) was found between $\alpha$-glycosidase inhibitory effect and caffeine of the extracts, and siginificant negative correlation between $\alpha$ amylase inhibition and tea polyphenols and total catechins, Pearson's correlation coefficients of which were -0.991 ( $p$ $<0.01)$ and $-0.959(p<0.05)$, respectively.

Table 3. Pearson correlation analysis between the main components in tea extracts and their bioactivity

\begin{tabular}{|c|c|c|c|c|c|c|c|c|c|c|c|c|}
\hline & Protein & $\begin{array}{c}\text { Tea } \\
\text { Polysaccharides }\end{array}$ & $\begin{array}{c}\text { Tea } \\
\text { Polyphenols }\end{array}$ & $\begin{array}{l}\text { Amino } \\
\text { acid }\end{array}$ & Caffeine & Catechin & EGCG & $\begin{array}{l}\mathrm{ABTS} \\
\left(\mathrm{EC}_{30}\right)\end{array}$ & $\begin{array}{l}\mathrm{DPPH} \\
\left(\mathrm{EC}_{30}\right)\end{array}$ & $\begin{array}{l}\text { FRAP } \\
(30 \mu \mathrm{g} / \mathrm{ml})\end{array}$ & $\begin{array}{c}\alpha- \\
\text { Amylase } \\
\left(E_{50}\right)\end{array}$ & $\begin{array}{c}\alpha \text {-Glycosidase } \\
\left(\mathrm{EC}_{30}\right)\end{array}$ \\
\hline Protein & 1.000 & -0.152 & -0.223 & -0.814 & 0.737 & -0.344 & -0.321 & 0.845 & 0.381 & 0.351 & 0.189 & 0.867 \\
\hline $\begin{array}{c}\text { Tea } \\
\text { Polysaccharides }\end{array}$ & & 1.000 & $0.959^{*}$ & -0.427 & -0.407 & $0.967^{*}$ & $0.985^{*}$ & $\begin{array}{c}- \\
0.624\end{array}$ & -0.350 & 0.616 & -0.915 & -0.389 \\
\hline Tea Polyphenols & & & 1.000 & -0.386 & -0.608 & $0.986^{*}$ & $0.964^{*}$ & $\begin{array}{c}- \\
0.708\end{array}$ & -0.600 & 0.379 & $-0.991^{* *}$ & -0.552 \\
\hline Amino Acid & & & & 1.000 & -0.334 & -0.262 & -0.271 & $\begin{array}{c}- \\
0.377\end{array}$ & 0.000 & -0.556 & 0.413 & -0.490 \\
\hline Caffeine & & & & & 1.000 & -0.627 & -0.532 & 0.886 & 0.900 & 0.449 & 0.649 & $0.974^{*}$ \\
\hline Catechin & & & & & & 1.000 & $0.990^{*}$ & $\begin{array}{c}- \\
0.784\end{array}$ & -0.546 & 0.401 & $-0.959^{*}$ & -0.608 \\
\hline EGCG & & & & & & & 1.000 & 0.749 & -0.422 & 0.514 & -0.919 & -0.534 \\
\hline $\operatorname{ABTS}\left(\mathrm{EC}_{30}\right)$ & & & & & & & & 1.000 & 0.634 & 0.079 & 0.684 & 0.943 \\
\hline $\mathrm{DPPH}\left(\mathrm{EC}_{30}\right)$ & & & & & & & & & 1.000 & 0.500 & 0.687 & 0.780 \\
\hline FRAP $(30 \mu \mathrm{g} / \mathrm{ml})$ & & & & & & & & & & 1.000 & -0.282 & 0.403 \\
\hline$\alpha$-Amylase (EC $\left.{ }_{50}\right)$ & & & & & & & & & & & 1.000 & 0.567 \\
\hline $\begin{array}{c}\alpha \text {-Glycosidase } \\
\left(\mathrm{EC}_{30}\right)\end{array}$ & & & & & & & & & & & & 1.000 \\
\hline
\end{tabular}




\section{Discussion}

As one of the most popular beverages in the world, teas are consumed not only because of their flavors, but also their potential health benefits, and both are attributed to their contained chemical constituents (Yang and Landau, 2000). As investigated in the present work, oolong tea was found to have the highest content $(31.56 \%)$ of tea ployphenols, which were almost 3-folds than that in black (11.69\%) tea. Similar results were observed in catechins, which were the main component in tea polyphenols. In manufacture of teas, suitability of tea variety is important for the special flavor and taste of a certain kind of tea. Large or middle leafed tea is more suitable for puerh tea and oolong tea, and small leafed tea is much better for green tea and black tea. Such difference in varieties is the main reason leading to the difference in chemicals of different teas, despite it can partly be explained by that tea polyphenols as antioxidants are instable and easily to be oxidized during deep fermentation (Haslam, 2003; Harbowy, 1997). It was reported that conjugation might occur between tea polyphenols and polysaccharides, resulting in complicated structure where partial protein and caffeine were involved and could not be isolated easily (Huang et al., 2013). This can be partly supported by the previous work on tea polysaccharides and tea pigments. It was found that high-purity tea polysacchrides or tea pigments (such as thearubigins, theabrownins) was difficult to prepared from fermentation teas despite various separation technology employed (Kuhnert, 2010; Bhattacharya et al., 2011; Gong et al., 2010). Even if relative pure samples were isolated in some cases, their bioactivities were always weaker than the crude extracts where they derived (Wang et al., 2013).

It is known that oxidative stress is associated with a wide range of diseases (Butterfield et al., 2007; Reuter et al., 2010), antioxidant properties of the extracts thus could be considered a preliminary index for their potential benefits for human health. In the present study, the antioxidant activities of extracts of four typical teas were evaluated by assays of DPPH, ABTS and FRAP respectively. In this study, green tea showed the best capacity of scavenging DPPH radicals, and oolong tea exhibited the strongest ability on scavenging ABTS radicals and ferric-reducing (Table 2). As known, tea polyphenols (tea catechins) are considered as the main antioxidants in teas (Harbowy, 1997). And the antioxidant capacity of tea polysaccharides was also highlighted in recently (Chen, 2004). Thus, the roles they played in the antioxidant activity of extracts of four typical teas were further analyzed by using Pearson's correlation coefficient (Table 3). Relative higher negative correlation was found between tea polypehnols (catechins and EGCG) and $\mathrm{IC}_{30}$ values of scavenging DPPH and ABTS, followed by those of tea polysaccharides, but no significance was observed. On the contrary, the correlation between tea polysaccharides and FRAP values was higher than those of tea polyphenols (catechins and EGCG), but still with no significance. Such results implied that antioxidant activity of teas might be partly or mainly contributed to tea polyphenols (mianly catechins) and tea polysacchrides, but it could not be contributed by them totally.

Hyperglycemia, a condition characterized by an abnormal postprandial increase in blood glucose level, has been linked to the onset of type 2 DM (Apostolidis and Lee, 2010). Effective control of postprandial hyperglycemia is important in early intervention and prevention of diabetic complications for type 2 diabetes management (Ratner, 2001). Pancreatic $\alpha$-amylase and $\alpha$ glycosidase are key enzymes in the carbohydrate digestion and considered as therapeutic targets for modulation of postprandial hyperglycemia (Tarling et al., 2008; Lebovitz, 1998; Krentz and Bailey, 2005). Previously, the potential inhibitory effect of teas and their main components were investigated along, but few literatures reported the different effect of various teas. In the present study, the inhibition on $\alpha$-amylase and $\alpha$-glycosidase of four typical teas were evaluated. And it was observed that oolong tea and green tea exhibited the strongest inhibition on $\alpha$ amylase and $\alpha$-glycosidase, respectively. And puerh tea showed the weakest inhibitory effect on both $\alpha$-amylase and $\alpha$-glycosidase, followed by black tea (Figure 4 and Figure 5). Phenolics derived from plant sources were suggested to have a potential application as $\alpha$-amylase or $\alpha$-glycosidase inhibitors. Previously, it was reported that tea polyphenols and tea polysaccharides had remarkable inhibitory effect on $\alpha$-amylase or $\alpha$-glycosidase, and were considered as the main constituents being charge of hypoglycemic of teas (Gao, 2013; Chen, 2008). Our results were consistent with that opinion. It can be seen the correlation between tea polyphenols and tea catechins and $\mathrm{EC}_{50}$ values of inhibition on $\alpha$-amylase were negatively higher $(-0.991$ and -0.959$)$ with significance ( $p$ $<0.01$ and $p<0.05$ ). Despite no significance was observed, a high correlation (-0.915) was found between tea polysacchrides and $\mathrm{EC}_{50}$ values of inhibition on $\alpha$ amylase. However, no obvious correlations were observed between the chemicals and inhibition on $\alpha$-glycosidase. Besides, it is interesting to note that a significant positive correlation $(0.974, p<0.05)$ was found between caffeine and $\mathrm{EC}_{30}$ of $\alpha$-glycosidase inhibition. Previously, it was found caffeine was not capable of suppressing $\alpha$ glycosidase, and contributed little to positive effect on modulation of coffee on diabetes (Cheng et al., 2011; Chen et al., 2011). Our results further showed caffeine may attenuate the potential inhibitory effect on $\alpha$ glycosidase of teas, which indicated that decaffeinated tea might be more suitable for the type 2 diabetes than normal tea. Of course, accurate conclusion should be drawn by more detailed experiments in future.

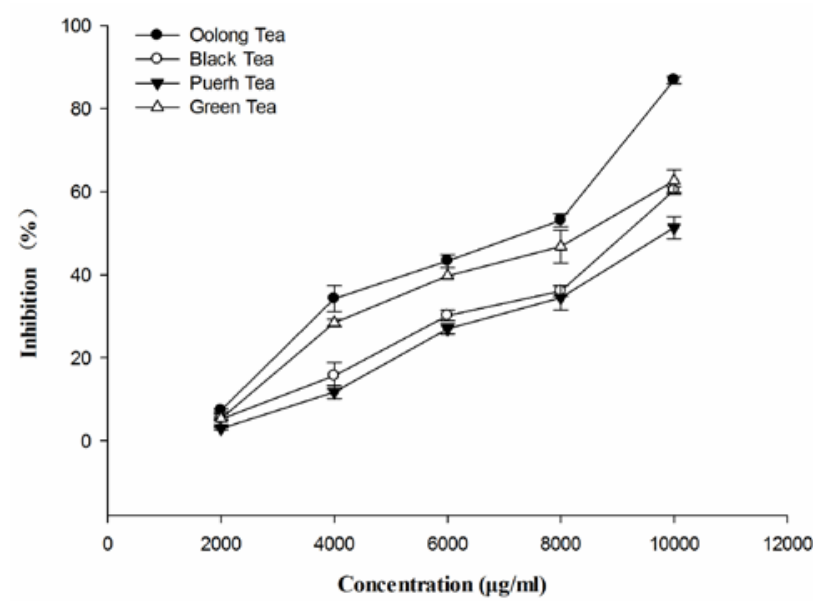

Figure 4. $\alpha$-Amylase inhibitory effect of the tea extracts 


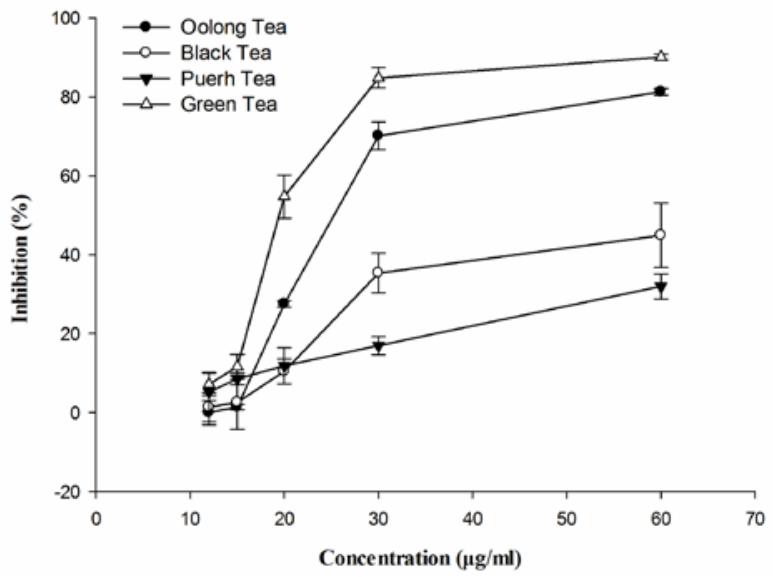

Figure 5. $\alpha$-Glycosidase inhibitory effect of the tea extracts

\section{Conclusions}

In conclusion, four typical teas had different chemical compositions, despite all of them derived from flesh tea leaves. Non-fermented (green tea) or semi-fermented (oolong tea) possessed stronger antioxidant activity and inhibitory potential on $\alpha$-amylase and $\alpha$-glycosidase than full-fermented (black tea) and post-fermented tea (puerh tea), which indicated that teas with no or slight fermentation was suitable and health beverage for who suffering from hyperglycemia. Furthermore, decaffeinated tea could be recommend due to caffeine had a negative effect on the $\alpha$-glycosidase inhibition of teas, although more detailed study was required.

\section{Conflict of Interest}

The authors declare that there are no conflicts of interest.

\section{Acknowledgements}

This work was supported by the Department of Education of Guangdong Province, P. R. China (No. 2012B091100165) and the Science and Technology Department of Zhejiang Province, P. R. China (No. 2010LM201-15).

\section{References}

[1] Apostolidis, E., Lee, C., 2010. In vitro potential of Ascophyllum nodosum phenolic antioxidant-mediated $\alpha$-glucosidase and $\alpha$ amylase inhibition. J. Food Sci. 75, H97-H102.

[2] Benzie, I.F.F., Strain, J., 1999. Ferric reducing/antioxidant power assay: Direct measure of total antioxidant activity of biological fluids and modified version for simultaneous measurement of total antioxidant power and ascorbic acid concentration. Method. Enzymol. 299, 15-27.

[3] Bhattacharya, U., Mukhopadhyay, S., Giri. A.K., 2011. Comparative Antimutagenic and Anticancer Activity of Three Fractions of Black Tea Polyphenols Thearubigins. Nutr. Cancer. 63 (7), 122-1132.

[4] Bradford, M.M., 1976. A rapid and sensitive method for the quantitation of microgram quantities of protein utilizing the principle of protein-dye binding. Anal. Biochem. 72 (1-2), 248254.
[5] Butterfield, D.A., Reed, T., Newman, S.F., Sultana, R., 2007. Roles of amyloid $\beta$-peptide-associated oxidative stress and brain protein modifications in the pathogenesis of Alzheimer's disease and mild cognitive impairment. Free Radic. Bio. Med. 43 (5), 658677.

[6] Cai, Y., Luo, Q., Sun, M., Corke, H., 2004. Antioxidant activity and phenolic compounds of 112 traditional Chinese medicinal plants associated with anticancer. Life Sci. 74, 2157-2184.

[7] Chen, C.C., Chuang, P.H., Chen, Y.S., Yao, C.H, Chen, H.M., 2011. Chip-based drug screening for inhibiting $\alpha$-glucosidase, Fitoterapia 82 (8), 49-1257

[8] Chen, H., Zhang, M., Qu Z., Xie, B., 2008. Antioxidant activities of different fractions of polysaccharide conjugates from green tea (Camellia Sinensis). Food Chem. 106 (2), 559-563.

[9] Chen, H., Zhang, M., Xie, B., 2004. Quantification of uronic acids in tea polysaccharide conjugates and their antioxidant properties. J. Agric. Food Chem. 52 (11), 3333-3336.

[10] Cheng, B., Liu, X., Gong, H., Huang, L., Chen, H., Zhang, X., et al., 2011. Coffee Components Inhibit Amyloid Formation of Human Islet Amyloid Polypeptide in Vitro: Possible Link between Coffee Consumption and Diabetes Mellitus. J. Agric. Food Chem. 59 (24), 147-13155.

[11] Gao, J., Xu, P., Wang, Y., Wang, Y., Hochstetter, D. 2013. Combined effects of green tea extracts, green tea polyphenols or epigallocatechin gallate with acarbose on inhibition against $\alpha$ amylase and $\alpha$-glucosidase in vitro. Molecules, 18 (9), 1161411623.

[12] Gong, J., Peng, C., Chen, T., Gao, B., Zhou, H., 2010. Effects of Theabrownin from Pu-erh Tea on the Metabolism of Serum Lipids in Rats: Mechanism of Action. J. Food Sci. 75 (6), H182-H189

[13] Harbowy, M.E., Balentine, D.A., Davies, A.P., Cai, Y., Tea Chemistry. 1997. Crit. Rev. Plant Sci. 16 (5), 415-480.

[14] Haslam, E., 2003. Thoughts on thearubigins. Phytochemistry. 64 (1): 61-73.

[15] Huang, Q.F., Chen, S.H., Chen, H., Wang, Y.F., Wang, Y.Q., Hochstetter, D., Xu, P., 2013. Studies on the bioactivity of aqueous extract of pu-erh tea and its fractions: In vitro antioxidant activity and a-glycosidase inhibitory property, and their effect on postprandial hyperglycemia in diabetic mice. Food Chem. Toxicol. 53, 75-83.

[16] Krentz, A.J., Bailey, C.J., 2005. Oral antidiabetic agents: current role in type 2 diabetes mellitus. Drugs 65, 385-411.

[17] Kuhnert, N., 2010. Unraveling the structure of the black tea thearubigins. Arch. Biochem. Biophys. 501 (1): 37-51

[18] Lebovitz, H.E., 1998. Postprandial hyperglycaemic state: importance and consequences. Diabetes Res. Clin. Pract. 40 (Suppl), 27-28.

[19] Liang, H., Liang, Y., Dong, J., Lu, J. Xu, H., Wang, H., 2007. Decaffeination of fresh green tea leaf (Camellia sinensis) by hot water treatment. Food Chem. 101, 1451-1456.

[20] Liang, Y., Zhang, L., Lu, J., 2005. A study on chemical estimation of pu-erh tea quality. J. Agric. Food Chem. 85 (3), 381-390.

[21] Lin, J.K., Lin-Shiau, S.Y., 2006. Mechanisms of hypolipidemic and anti-obesity effects of tea and tea polyphenols. Mol. Nutr. Food Res. 50, 211-217.

[22] Mohsen, S.M., Ammar, A.S.M., 2009. Total phenolic contents and antioxidant activity of corn tassel extracts. Food Chem. 112, 595598.

[23] Morris, D,L., 1948. Quantitative determination of carbohydrates with Dreywood's anthrone reagent. Science 107 (2775), 254-255.

[24] Ranilla, L.G., Kwon, Y.I., Apostolidis, E., Shetty, K., 2010. Phenolic compounds, antioxidant activity and in vitro inhibitory potential against key enzymes relevant for hyperglycemia and hypertension of commonly used medicinal plants, herbs and spices in Latin America. Bioresource Technol. 101, 4676-4689.

[25] Ratner, R. E..2001. Controlling postprandial hyperglycemia. Am. J. Cardiol. 88 (6A), 26-31.

[26] Reuter, S., Gupta, S.C., Chaturvedi, M.M., Aggarwal, B.B., 2010. Oxidative stress, inflammation, and cancer: how are they linked? Free Radic. Bio. Med. 49 (11), 1603-1616.

[27] Tarling, C.A., Woods, K., Zhang, R., Brastianos, H.C., Brayer G.D., Andersen, R.J., Withers, S.G., 2008. The search for novel human pancreatic $\alpha$-mylase inhibitors: High-throughput screening of terrestrial and marine natural product extracts. ChemBioChem 9 433-438.

[28] Wang, B.S., Yu, H., Chang, L.W., Yen, W.J., Duh, P.D., 2008. Protective effects of pu-erh tea on LDL oxidation and nitric oxide 
generation in macrophage cells. LWT-Food Sci. Technol. 41, $1122-1132$.

[29] Wang, D.F., Wang, C.H., Li, J., Zhao, G.W., 2001. Components and activity of polysaccharides from coarse tea. J. Agric. Food Chem. 49, 507-510.

[30] Wang, C., 1988. Ed. Tea Biochemistry; Agricultural Press: Beijing, China, 289-301 (In Chinese).

[31] Wang, Y., Shao, S., Xu, P., Chen, H., Lin-Shiau, S.Y., Deng, Y.T., Lin, J.K., 2012. Fermentation process enhanced production and bioactivities of oolong tea polysaccharides. Food Res. Int. 46(1), 58-166

[32] Wang, Y., Zhao, Y., Andrae-Marobela, K., Okatch, H., Xiao. J., 2013, Tea polysaccharides as food antioxidants: An old woman’s tale?. Food Chem. 138 (2-3), 1923-1927.
[33] Xu, P., Wu, J., Zhang, Y., Chen, H., Wang, Y.F., 2014 Physicochemical characterization of puerh tea polysaccharides and their antioxidant and alpha-glycosidase inhibition. J. Funct. Foods 6, 545-554.

[34] Yang, C.S., Landau, J.M., 2000. Effects of tea consumption on nutrition and health. J. Nutr. 130 (10), 2409-2412.

[35] Zhou, X.L., Wang, D.F., Sun, P.N., Peter, B., Li, L., Hou, Y.F., Wang, J.F., 2007. Effects of soluble tea polysaccharides on hyperglycemia in alloxan-diabetic mice. J. Agric. Food Chem. 5, 5523-5528. 